\title{
Annual Report on the External Quality Assessment Scheme for Hormones in Korea (2017)
}

Hyung-Doo Park

Department of Laboratory Medicine and Genetics, Samsung Medical Center, Sungkyunkwan University School of Medicine, Seoul, Korea

Corresponding author: Hyung-Doo Park Department of Laboratory Medicine and Genetics, Samsung Medical Center, Sungkyunkwan University School of Medicine, 81 Irwon-ro, Gangnam-gu, Seoul 06351, Korea

Tel: $+82-2-3410-0290$

Fax: +82-2-3410-2719

E-mail: nayadoo@hanmail.net

In 2017, the Korean Association of External Quality Assessment Service developed a hormone proficiency testing program that comprised 11 test items for hormone I and four test items for hormone II. This program was conducted twice a year using three-level control materials. Data and results of each test item were analyzed by the respective institutions according to the test instruments. The report was prepared by dividing it into a common report that showed the characteristics of the overall participating institutions and an organization-specific report that showed the assessment data of individual institutions. The following statistical data were presented: the number of participating institutions per group, mean, standard deviation, coefficient of variation, median, minimum value, and maximum value. The individual report was composed of a table, histogram, and Levey-Jennings chart showing the statistics for each test item. The results of the assessment of each institution and the statistical data for each classification are presented in a table, and a standard deviation index was provided for both the company classification and classification by instruments. Although the total number of participating institutions and distribution of test instruments were not significantly different from the previous year, the number of participating institutions varied by test item. The coefficient of variation tended to be relatively high for each test item because the concentration of quality control materials was low and the number of participating institutions was small. I believe that these statistical analysis data are useful for analyzing external quality control results of the institutions and selecting an immunoassay test instrument for hormones.

(J Lab Med Qual Assur 2018;40:77-84)

Key Words: Korean Association of External Quality Assessment Service, Laboratory proficiency testing, Hormones

\section{서론}

대한임상검사정도관리협회에서는 2015년까지 운영해오던 분과 프로그램의 운영방식을 2016년부터 차세대 신빙도조사 사업 체계로 변경하면서 46개 소분류상 프로그램 단위별 운영 체계로 전환하였다[1-3]. 임상화학 분야는 중분류상으로 소변 · 대변 · 체액 · 결석검사, 일반화학검사, 혈액가스·전해질·이 온검사, 대사물질검사, 단백면역검사, 탄수화물 - 지질 - 단백 질 · 비타민검사, 호르몬검사, 종양표지자검사, 약물검사, 정확 도기반검사 등 10 가지의 프로그램으로 구성되어 있고, 중분류 검사프로그램에는 각각 $1-4$ 가지의 소분류 프로그램이 포함 되어 있다[4]. 호르몬검사프로그램은 2016년에 호르몬검사 I
로 시작하여 2017년에 호르몬검사 II가 추가되었다. 호르몬검 사 I에서 시행되는 검사항목은 thyroid stimulating hormone (TSH)을 포함한 11 가지로 선정되었다. 호르몬검사 II에는 vitamin D 등 4가지 검사가 추가되었다. 이에 2017년에 실시 되었던 호르몬검사프로그램에 대한 신빙도조사사업 결과를 분석하여 보고하고자 한다.

\section{재료 및 방법}

1. 대상

호르몬검사프로그램은 연 2회에 걸쳐 회차별로 3 개의 정도 관리물질을 사용하여 수행되었다. 냉장상태가 유지될 수 있 


\section{Journal of LABORATORY MEDICINE and QUALITY ASSURANCE}

\section{Hyung-Doo Park • Annual Report on KEQA for Hormones (2017)}

도록 아이스팩이 내장된 특수 제작박스에 정도관리물질을 넣 어서 참여 등록기관을 대상으로 호르몬검사 I 프로그램 물질 은 5월 15일(1차)과 10월 16일(2차)에, 호르몬검사 II 프로그 램 물질은 3월 6일(1차)과 8월 29일(2차)에 각각 발송하였다 (Tables 1, 2).

\section{2. 정도관리물질과 검사항목}

정도관리물질은 Bio-Rad사의 Lyphochek Immunossay Control (Bio-Rad Laboratories, Hercules, CA, USA) 등 사람 혈청을 기질로 한 액상 제품을 사용하였다. 호르몬검 사 I 프로그램의 검사항목은 TSH, total thyroxine (TT4), free thyroxine (FT4), total triiodothyronine (TT3), thyroglobulin, total human chorionic gonadotropin (hCG), testosterone, estradiol (E2), 17-hydroxyprogesterone (17$\mathrm{OHP}$ ), progesterone, prolactin 등 11가지였다. 호르몬검사 II 프로그램의 검사항목은 total 25-hydroxy vitamin D (Vit D), procalcitonin, parathyroid hormone (PTH), erythropoietin 등 4 가지였다. 정도관리물질을 수령한 참여기관에서는 검사 시행 후 지정된 회신 마감일 이내에 대한임상검사정도관리협 회 신빙도조사사업 홈페이지(http://eqas.keqas.org)에 결과 를 입력하도록 안내하였다.

Table 1. Baseline data used in proficiency tests for hormone I in 2017

\begin{tabular}{lcc}
\hline \multirow{2}{*}{ Variable } & \multicolumn{2}{c}{ Trial } \\
\cline { 2 - 3 } & 1st & 2nd \\
\hline Delivery date & 2017.5 .15 & 2017.10 .16 \\
Response date & 5.26 & 2017. 10. 16- \\
& & \\
Test & 505 & 565 \\
Thyroid stimulating hormone & 501 & 557 \\
Free thyroxin (T4) & 453 & 498 \\
Total triiodothyronine (T3) & 78 & 80 \\
Thyroglobulin & 141 & 149 \\
Total human chorionic & & \\
$\quad$ gonadotropin & 92 & 95 \\
Testosterone & 114 & 123 \\
Estradiol (E2) & 4 & 33 \\
17-Hydroxyprogesterone & 29 & 101 \\
Progesterone & 95 & 91 \\
Prolactin & 93 & \\
Total thyroxine (T4) & & \\
\hline
\end{tabular}

\section{3. 결과 판정 및 분석}

각 검사항목에 대해 개별 기관에서 입력한 검사기기, 시약, 검사결과 등에 따라 통계분석을 시행하였고, 이 통계값을 바탕 으로 전체 참여기관의 특성을 보여주는 공통보고서와 개별기 관의 평가자료를 보여주는 기관별 보고서로 나누어 보고하였 다. 공통보고서는 전체 참여기관, 동일 기기회사 사용기관, 동 일 기기 사용기관 등 3 단계로 그룹화하여 통계값을 제시하였 다(Fig. 1). 전체 참여기관에 해당하는 통계, 기기회사를 기준 분류로 한 그룹의 통계, 특정 검사기기로 구분한 그룹의 통계 를 처리하여 각각 제시하였다. 제시된 통계에는 각 그룹별 참 여기관 수, 평균, 표준편차, 변동계수, 중앙값, 최소값, 최대값 등이 포함되어 있다. 이상치를 제거하지 않은 상태의 모든 참 여기관의 정보를 이용하여 중앙값, 최소값, 최대값 등을 구했 고, 적절한 방법으로 이상치를 제거한 후의 자료를 바탕으로 평균, 표준편차, 변동계수 등을 계산하여 제시하였다. 한편, 임 상검사정도관리협회의 원칙에 따라 동일 그룹에 속한 기관 수 가 10 개 미만인 경우에는 평균, 표준편차, 변동계수 등을 제시 하지 않았고, 기관 수가 3 개 미만인 경우에는 중앙값도 제시 하지 않았다. 이상치는 Tukey rule을 이용하여 제거하였는데, 각 해당 분류에서 75 percentile 값(Q3)과 25 percentile 값 (Q1)의 차(Q3-Q1; interquartile range, $\mathrm{IQR})$ 의 1.5배를 초 과하여 $\mathrm{Q} 1$ 보다 낮거나 $\mathrm{Q} 3$ 보다 높은 결과값 $(<\mathrm{Q} 1-1.5 \times \mathrm{IQR}$ 또는 $>\mathrm{Q} 3+1.5 \times \mathrm{IQR})$ 으로 설정하였다.

기관별 보고서는 각 검사항목별로 통계치를 보여주는 표, 히 스토그램, 레비-제닝스 차트(Levey-Jennings chart)로 구성 하여 일목요연하게 볼 수 있도록 하였다(Fig. 2). 통계치를 제 시한 표에는 각 기관의 결과값과 각 분류별 통계치를 제시하였 고, 표준편차지수(standard deviation index, SDI)는 기준분 류와 세분류에서만 제시하였다. 전체 참여기관 자료와 각 그룹 별 참여기관의 수가 10 개 미만일 경우에는 평균, 표준편차, 변

Table 2. Baseline data used in proficiency tests for hormone II in 2017

\begin{tabular}{lrc}
\hline \multirow{2}{*}{\multicolumn{1}{c}{ Variable }} & \multicolumn{2}{c}{ Trial } \\
\cline { 2 - 3 } & 1st & 2nd \\
\hline Delivery date & 2017.3 .6 & 2017. 8. 29 \\
Response date & $2017.3 .6-3.17$ & $2017.8 .29-9.8$ \\
Test & & \\
Intact parathyroid hormone & 112 & 117 \\
Erythropoietin & 7 & 6 \\
Total 25-hydroxy vitamin D & 131 & 135 \\
Procalcitonin & 142 & 149 \\
\hline
\end{tabular}




\begin{tabular}{|c|c|c|c|c|c|c|c|}
\hline 2017년 1차 호르몬검사 공통 보그서 & rmo & {$[\mu]$} & & & & & \\
\hline CH-17-01 Thyroid stimulating hormo & $\mathrm{N}$ & Mean & SD & $\mathrm{Cv}(\%)$ & Median & Min & Max \\
\hline All & 505 & 0.759 & 0.084 & 11.0 & 0.73 & 0.32 & 1.40 \\
\hline 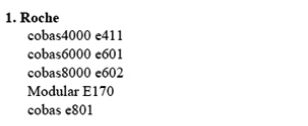 & $\begin{array}{r}211 \\
75 \\
63 \\
42 \\
26 \\
5\end{array}$ & $\begin{array}{l}0.845 \\
0.851 \\
0.836 \\
0.834 \\
0.845\end{array}$ & $\begin{array}{l}0.024 \\
0.036 \\
0.022 \\
0.021 \\
0.0215\end{array}$ & $\begin{array}{l}2.9 \\
4.2 \\
2.7 \\
2.5 \\
1.8\end{array}$ & $\begin{array}{l}0.85 \\
0.86 \\
0.84 \\
0.85 \\
0.85 \\
0.85\end{array}$ & $\begin{array}{l}0.74 \\
0.78 \\
0.74 \\
0.77 \\
0.81 \\
0.80\end{array}$ & $\begin{array}{l}1.40 \\
0.97 \\
0.98 \\
0.89 \\
1.40 \\
0.88\end{array}$ \\
\hline $\begin{array}{l}\text { 2. Abbott } \\
\text { ARRHECT izeoo } \\
\text { ARCHITECT i ilooo }\end{array}$ & $\begin{array}{r}142 \\
103 \\
39\end{array}$ & $\begin{array}{l}0.706 \\
0.711 \\
0.699\end{array}$ & $\begin{array}{l}0.022 \\
0.025 \\
0.019\end{array}$ & $\begin{array}{l}3.2 \\
3.5 \\
2.7\end{array}$ & $\begin{array}{l}0.71 \\
0.71 \\
0.70\end{array}$ & $\begin{array}{l}0.54 \\
0.57 \\
0.54\end{array}$ & $\begin{array}{l}0.79 \\
0.79 \\
0.73\end{array}$ \\
\hline 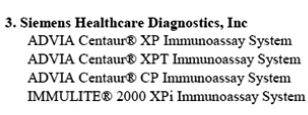 & $\begin{array}{r}90 \\
66 \\
18 \\
3 \\
2\end{array}$ & $\begin{array}{l}0.706 \\
0.707 \\
0.706\end{array}$ & $\begin{array}{l}0.022 \\
0.020 \\
0.025\end{array}$ & $\begin{array}{l}3.1 \\
2.8 \\
3.5\end{array}$ & $\begin{array}{l}0.71 \\
0.711 \\
0.71 \\
0.65\end{array}$ & $\begin{array}{l}0.32 \\
0.44 \\
0.66 \\
0.32 \\
0.67\end{array}$ & $\begin{array}{l}0.78 \\
0.78 \\
0.76 \\
0.69 \\
0.74\end{array}$ \\
\hline $\begin{array}{l}\text { 4. Beckman Coulter Inc. } \\
\text { Unicel Dxi800 } \\
\text { Access2 }\end{array}$ & $\begin{array}{l}37 \\
25 \\
11\end{array}$ & $\begin{array}{l}0.675 \\
0.669 \\
0.685\end{array}$ & $\begin{array}{l}0.038 \\
0.037 \\
0.039\end{array}$ & $\begin{array}{l}5.6 \\
5.5 \\
5.7\end{array}$ & $\begin{array}{l}0.66 \\
0.06 \\
0.69\end{array}$ & $\begin{array}{l}0.45 \\
0.01 \\
0.45\end{array}$ & $\begin{array}{l}0.75 \\
0.75 \\
0.75\end{array}$ \\
\hline $\begin{array}{l}\text { 5. Biomerieux } \\
\text { Miniv vidas } \\
\text { Vidas }\end{array}$ & $\begin{array}{r}14 \\
7 \\
6\end{array}$ & 0.696 & 0.021 & 3.0 & $\begin{array}{l}0.70 \\
0.70 \\
0.72\end{array}$ & $\begin{array}{l}0.61 \\
0.05 \\
0.61\end{array}$ & $\begin{array}{l}1.00 \\
0.71 \\
1.00\end{array}$ \\
\hline $\begin{array}{l}\text { 6. Fujirebio INC. } \\
\text { Lumipulse G1200 }\end{array}$ & ${ }_{5}^{5}$ & & & & $\begin{array}{l}0.62 \\
0.62\end{array}$ & $\begin{array}{l}0.55 \\
0.55\end{array}$ & $\begin{array}{l}0.65 \\
0.65\end{array}$ \\
\hline 7. Ortho Clinical Diagnostics & 4 & & & & 0.59 & 0.55 & 0.62 \\
\hline 8. Tosoh & 2 & & & & & 0.68 & 0.70 \\
\hline (2A) 대함잉상사장조관리열의 & & & & & & & $6 / 29$ \\
\hline
\end{tabular}

Fig. 1. Summary report of the general statistics report for the hormone I proficiency testing program of the 2017 Korean External Quality Assessment Service.

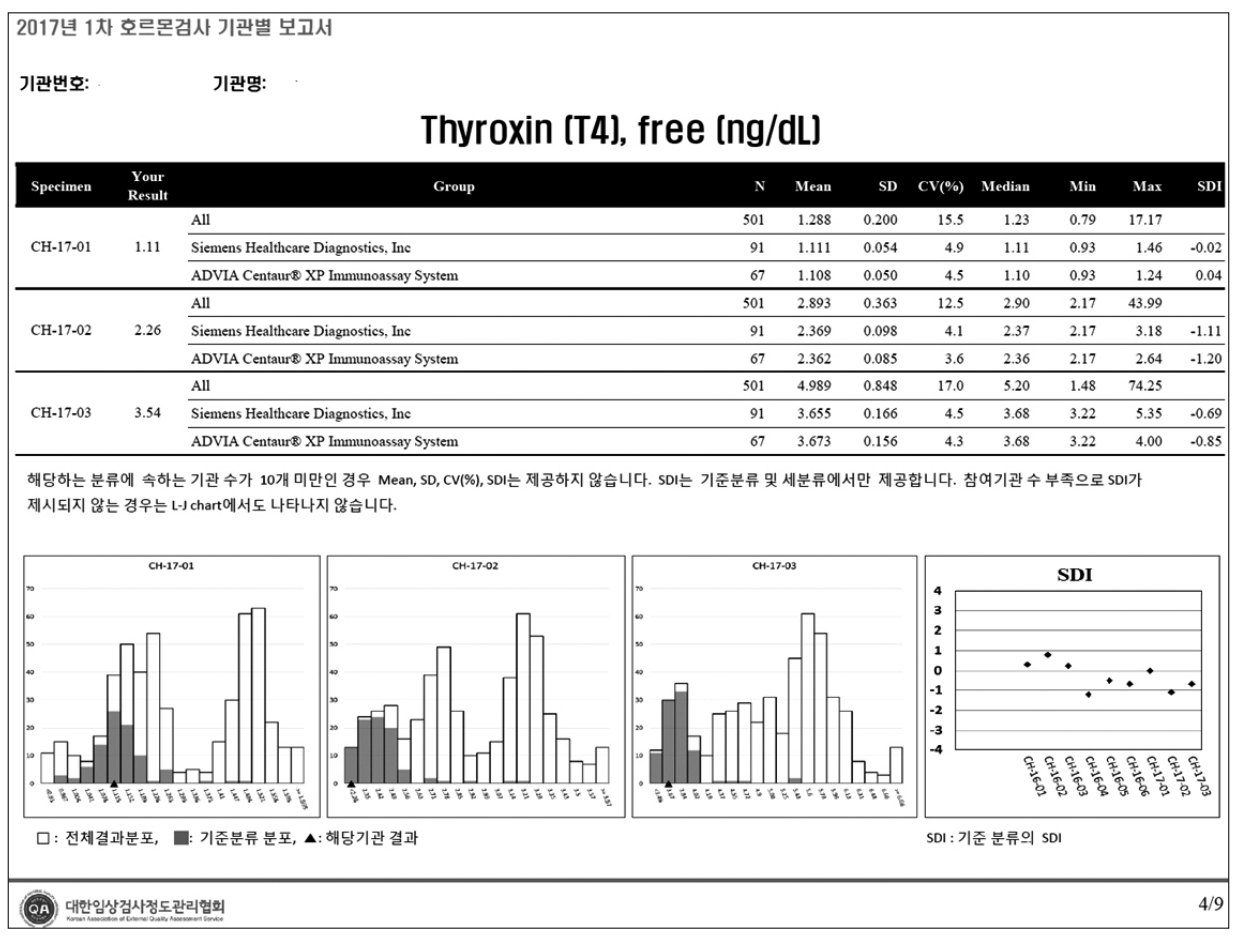

Fig. 2. An example of an individual institutional report for the hormone II proficiency testing program of the 2017 Korean External Quality Assessment Service.
이계수, SDI 등을 제시하지 않았다. 레비-제닝스 차트는 기준 분류별 SDI를 이용하여 작성하였는데, 참여기관 수 부족으로 $\mathrm{SDI}$ 가 제시되지 않는 경우는 레비-제닝스 차트에서도 표시되 지 않도록 하였다. 히스토그램에서는 전체 참여기관의 분포와
기준분류별 분포를 제시하였고 각 기관의 위치를 표시하였다 히스토그램의 첫 번째와 마지막 막대는 각각 전체 참여기관의 결과분포에서 2.5 퍼센타일 미만과 97.5 퍼센타일 이상에 해당 한다. 


\section{Journal of LABORATORY MEDICINE and QUALITY ASSURANCE}

Hyung-Doo Park • Annual Report on KEQA for Hormones (2017)

Table 3. Proficiency test results for hormone I in 2017

\begin{tabular}{|c|c|c|c|c|c|}
\hline Test & $\begin{array}{c}\text { No. of } \\
\text { participants }\end{array}$ & Quality control no. & $\begin{array}{c}\text { Mean } \pm \text { standard } \\
\text { deviation }\end{array}$ & $\begin{array}{l}\text { Coefficient of } \\
\text { variation (\%) }\end{array}$ & $\begin{array}{c}\text { Median } \\
(\min -\max )\end{array}$ \\
\hline \multicolumn{6}{|l|}{1 st } \\
\hline \multirow[t]{3}{*}{ TSH } & 505 & CH-17-01 & $0.759 \pm 0.084$ & 11.0 & $0.73(0.32-1.40)$ \\
\hline & & CH-17-02 & $4.992 \pm 0.325$ & 6.5 & $4.96(1.85-6.98)$ \\
\hline & & $\mathrm{CH}-17-03$ & $25.805 \pm 1.813$ & 7.0 & $25.90(0.69-42.21)$ \\
\hline \multirow[t]{3}{*}{ Free T4 } & 501 & $\mathrm{CH}-17-01$ & $1.288 \pm 0.200$ & 15.5 & $1.23(0.79-17.17)$ \\
\hline & & $\mathrm{CH}-17-02$ & $2.893 \pm 0.363$ & 12.5 & $2.90(2.17-43.99)$ \\
\hline & & $\mathrm{CH}-17-03$ & $4.989 \pm 0.848$ & 17.0 & $5.20(1.48-74.25)$ \\
\hline \multirow[t]{3}{*}{ Total T3 } & 453 & $\mathrm{CH}-17-01$ & $1.093 \pm 0.169$ & 15.4 & $1.07(0.73-14.43)$ \\
\hline & & $\mathrm{CH}-17-02$ & $1.840 \pm 0.203$ & 11.0 & $1.89(1.31-26.65)$ \\
\hline & & $\mathrm{CH}-17-03$ & $2.911 \pm 0.355$ & 12.2 & $3.01(0.77-36.45)$ \\
\hline \multirow{3}{*}{ Thyroglobulin } & 78 & $\mathrm{CH}-17-01$ & $3.46 \pm 0.10$ & 2.8 & $3.50(2.5-30.2)$ \\
\hline & & $\mathrm{CH}-17-02$ & $2.41 \pm 0.17$ & 6.9 & $2.40(1.9-106.4)$ \\
\hline & & $\mathrm{CH}-17-03$ & $5.40 \pm 0.17$ & 3.1 & $5.40(4.1-172.0)$ \\
\hline \multirow[t]{3}{*}{ Total hCG } & 141 & $\mathrm{CH}-17-01$ & $3.08 \pm 0.32$ & 10.5 & $3.10(2.3-25.0)$ \\
\hline & & $\mathrm{CH}-17-02$ & $19.14 \pm 1.29$ & 6.8 & $19.2(16.1-50.0)$ \\
\hline & & $\mathrm{CH}-17-03$ & $352.92 \pm 16.53$ & 4.7 & $354.2(312.7-500.0)$ \\
\hline \multirow{3}{*}{ Testosterone } & 92 & $\mathrm{CH}-17-01$ & $1.0044 \pm 0.0597$ & 5.9 & $0.9995(0.500-9.750)$ \\
\hline & & $\mathrm{CH}-17-02$ & $5.1811 \pm 0.6673$ & 12.9 & $5.4500(2.820-40.944)$ \\
\hline & & $\mathrm{CH}-17-03$ & $12.7386 \pm 1.4386$ & 11.3 & $13.195(6.420-95.457)$ \\
\hline \multirow[t]{3}{*}{ Estradiol (E2) } & 114 & $\mathrm{CH}-17-01$ & $41.52 \pm 4.91$ & 11.8 & $42.95(27.6-103.0)$ \\
\hline & & $\mathrm{CH}-17-02$ & $311.33 \pm 66.35$ & 21.3 & $280.25(212.5-500.6)$ \\
\hline & & $\mathrm{CH}-17-03$ & $799.70 \pm 210.45$ & 26.3 & $701.30(547.2-1,253.6)$ \\
\hline \multirow[t]{3}{*}{ 17-OHP } & 4 & $\mathrm{CH}-17-01$ & $0.473 \pm 0.012$ & 2.4 & $0.480(0.46-0.56)$ \\
\hline & & $\mathrm{CH}-17-02$ & $2.358 \pm 0.186$ & 7.9 & $2.340(2.15-2.60)$ \\
\hline & & $\mathrm{CH}-17-03$ & $4.830 \pm 0.464$ & 9.6 & $4.735(4.38-5.47)$ \\
\hline \multirow[t]{3}{*}{ Progesterone } & 29 & $\mathrm{CH}-17-01$ & $0.946 \pm 0.161$ & 17.0 & $0.91(0.60-2.12)$ \\
\hline & & $\mathrm{CH}-17-02$ & $9.835 \pm 1.191$ & 12.1 & $10.25(7.00-17.75)$ \\
\hline & & $\mathrm{CH}-17-03$ & $22.592 \pm 4.064$ & 18.0 & $24.21(15.50-38.26)$ \\
\hline \multirow[t]{3}{*}{ Prolactin } & 95 & $\mathrm{CH}-17-01$ & $8.733 \pm 1.751$ & 20.0 & $8.77(0.52-11.68)$ \\
\hline & & $\mathrm{CH}-17-02$ & $19.821 \pm 4.673$ & 23.6 & $19.91(11.93-26.94)$ \\
\hline & & $\mathrm{CH}-17-03$ & $50.202 \pm 11.515$ & 22.9 & $49.16(33.15-68.77)$ \\
\hline \multirow[t]{3}{*}{ Total T4 } & 93 & $\mathrm{CH}-17-01$ & $9.044 \pm 0.730$ & 8.1 & $8.89(7.10-11.60)$ \\
\hline & & $\mathrm{CH}-17-02$ & $12.203 \pm 0.686$ & 5.6 & $12.24(9.10-15.40)$ \\
\hline & & $\mathrm{CH}-17-03$ & $15.673 \pm 1.664$ & 10.6 & $15.70(11.24-19.84)$ \\
\hline \multicolumn{6}{|l|}{ 2nd } \\
\hline \multirow[t]{3}{*}{ TSH } & 565 & $\mathrm{CH}-17-04$ & $0.780 \pm 0.062$ & 8.0 & $0.79(0.57-30.01)$ \\
\hline & & $\mathrm{CH}-17-05$ & $5.667 \pm 0.715$ & 12.6 & $5.54(0.73-33.92)$ \\
\hline & & $\mathrm{CH}-17-06$ & $30.073 \pm 4.236$ & 14.1 & $29.70(0.84-43.52)$ \\
\hline
\end{tabular}


Journal of LABORATORY MEDICINE and QUALITY ASSURANCE

Hyung-Doo Park • Annual Report on KEQA for Hormones (2017)

Table 3. Continued

\begin{tabular}{|c|c|c|c|c|c|}
\hline Test & $\begin{array}{c}\text { No. of } \\
\text { participants }\end{array}$ & Quality control no. & $\begin{array}{c}\text { Mean } \pm \text { standard } \\
\text { deviation }\end{array}$ & $\begin{array}{l}\text { Coefficient of } \\
\text { variation }(\%)\end{array}$ & $\begin{array}{c}\text { Median } \\
(\min -\max )\end{array}$ \\
\hline \multirow[t]{3}{*}{ Free T4 } & 557 & $\mathrm{CH}-17-04$ & $0.992 \pm 0.150$ & 15.1 & $1.01(0.62-15.19)$ \\
\hline & & $\mathrm{CH}-17-05$ & $2.507 \pm 0.393$ & 15.7 & $2.51(1.28-44.47)$ \\
\hline & & CH-17-06 & $4.273 \pm 0.871$ & 20.4 & $4.30(1.22-68.12)$ \\
\hline \multirow[t]{3}{*}{ Total T3 } & 498 & $\mathrm{CH}-17-04$ & $1.038 \pm 0.143$ & 13.8 & $1.01(0.69-13.23)$ \\
\hline & & CH-17-05 & $1.982 \pm 0.181$ & 9.1 & $2.02(1.29-23.14)$ \\
\hline & & $\mathrm{CH}-17-06$ & $2.964 \pm 0.348$ & 11.7 & $3.06(1.74-34.24)$ \\
\hline \multirow[t]{3}{*}{ Thyroglobulin } & 80 & CH-17-04 & $3.73 \pm 0.13$ & 3.4 & $3.70(2.5-31.6)$ \\
\hline & & $\mathrm{CH}-17-05$ & $6.19 \pm 0.20$ & 3.2 & $6.20(4.6-55.8)$ \\
\hline & & $\mathrm{CH}-17-06$ & $5.68 \pm 0.19$ & 3.3 & $5.70(4.2-117.0)$ \\
\hline \multirow[t]{3}{*}{ Total hCG } & 149 & $\mathrm{CH}-17-04$ & $2.36 \pm 0.41$ & 17.2 & $2.30(1.8-7.4)$ \\
\hline & & $\mathrm{CH}-17-05$ & $19.03 \pm 1.56$ & 8.2 & $18.9(14.7-50.0)$ \\
\hline & & $\mathrm{CH}-17-06$ & $389.52 \pm 21.47$ & 5.5 & $391.0(337.8-647.0)$ \\
\hline \multirow[t]{3}{*}{ Testosterone } & 95 & $\mathrm{CH}-17-04$ & $0.9288 \pm 0.0663$ & 7.1 & $0.930(0.279-1.200)$ \\
\hline & & $\mathrm{CH}-17-05$ & $3.8974 \pm 0.5956$ & 15.3 & $4.132(1.930-4.720)$ \\
\hline & & $\mathrm{CH}-17-06$ & $9.2975 \pm 1.2307$ & 13.2 & $9.700(4.390-11.200)$ \\
\hline \multirow[t]{3}{*}{ Estradiol (E2) } & 123 & $\mathrm{CH}-17-04$ & $53.03 \pm 6.06$ & 11.4 & $55.0(34.0-147.0)$ \\
\hline & & $\mathrm{CH}-17-05$ & $279.90 \pm 61.39$ & 21.9 & $248.0(205.0-505.2)$ \\
\hline & & $\mathrm{CH}-17-06$ & $635.18 \pm 182.70$ & 28.8 & $537.0(440.0-1,016.8)$ \\
\hline \multirow[t]{3}{*}{ 17-OHP } & 3 & $\mathrm{CH}-17-04$ & $0.613 \pm 0.040$ & 6.6 & $0.62(0.57-0.65)$ \\
\hline & & $\mathrm{CH}-17-05$ & $1.880 \pm 0.082$ & 4.4 & $1.90(1.79-1.95)$ \\
\hline & & $\mathrm{CH}-17-06$ & $3.630 \pm 0.104$ & 2.9 & $3.68(3.51-3.70)$ \\
\hline \multirow[t]{3}{*}{ Progesterone } & 33 & $\mathrm{CH}-17-04$ & $0.743 \pm 0.115$ & 15.4 & $0.74(0.54-1.75)$ \\
\hline & & $\mathrm{CH}-17-05$ & $9.488 \pm 1.389$ & 14.6 & $9.71(7.27-17.95)$ \\
\hline & & $\mathrm{CH}-17-06$ & $25.324 \pm 6.095$ & 24.1 & $25.40(17.20-44.93)$ \\
\hline \multirow[t]{3}{*}{ Prolactin } & 101 & $\mathrm{CH}-17-04$ & $8.726 \pm 1.495$ & 17.1 & $8.841(6.27-11.88)$ \\
\hline & & $\mathrm{CH}-17-05$ & $20.744 \pm 3.902$ & 18.8 & $20.49(13.50-27.75)$ \\
\hline & & CH-17-06 & $51.301 \pm 9.428$ & 18.4 & $50.73(36.18-69.71)$ \\
\hline \multirow[t]{3}{*}{ Total T4 } & 91 & $\mathrm{CH}-17-04$ & $7.617 \pm 0.750$ & 9.8 & $7.59(5.91-9.90)$ \\
\hline & & CH-17-05 & $10.664 \pm 0.725$ & 6.8 & $10.64(8.55-13.10)$ \\
\hline & & CH-17-06 & $13.644 \pm 1.425$ & 10.4 & $13.40(10.33-17.37)$ \\
\hline
\end{tabular}

Abbreviations: TSH, thyroid-stimulating hormone; T4, thyroxine; T3, triiodothyronine; hCG, human chorionic gonadotropin; 17-OHP, 17-hydroxyprogesterone.

\section{결과 및 고찰}

100 개 이상의 기관이 참여하는 검사항목은 호르몬검사 I 프 로그램에서 TSH, TT4, FT4, TT3, hCG, E2 등 6가지였으며, 호르몬검사 II 프로그램에서 PTH, Vit D, procalcitonin 등 3 가지였다. 17-OHP와 erythropoietin은 각각 4기관과 7기관으 로 전체 참여기관이 10 곳에 미치지 않았다. 대부분의 항목에
서는 전년도와 비슷하거나 소폭 증가한 참여기관 수를 보였다. 갑상선기능검사 관련 항목들의 신빙도조사사업 참여기관 증 가 폭이 큰 편이었는데, TSH검사의 경우 2016년 신빙도조사 에서 471기관, 2017년 1차에서 505기관, 2017년 2차에서 565 기관이 참여하여 1 년 동안 약 $20 \%$ 의 참여기관 수의 증가를 보 였다. 17-OHP과 TT4를 제외한 대부분의 호르몬검사 I 항목 에서 1 차 신빙도조사보다 2 차 조사에서 참여기관의 수가 증가 


\section{Journal of LABORATORY MEDICINE and QUALITY ASSURANCE}

\section{Hyung-Doo Park • Annual Report on KEQA for Hormones (2017)}

하였다.

호르몬검사 I과 호르몬검사 II과 항목들에 대한 두 차례의 신빙도조사에서 전체 참여기관의 통계값을 각각 Table 3과 Table 4에 정리하였다. 호르몬검사는 대부분 전용시약과 기기 를 사용하는데, 2 차 신빙도조사에서 참여기관이 565 곳으로 가 장 많았던 TSH검사의 경우, 7 개 회사에서 17 종류의 검사기기 가 사용되고 있었다. 1 차 신빙도조사 때 $\mathrm{TSH}$ 검사의 전체 기 관 정밀도는 변이계수 $(\%)$ 가 $\mathrm{CP}-17-01,-02,-03$ 물질에서 각 각 $11.0 \%, 6.5 \%, 7.0 \%$ 로 $10 \%$ 내외를 보였지만, 최소값과 최 대값의 차이가 무척 큰 현상이 세 가지 정도관리물질에서 공통 적으로 관찰되었다. TSH CP-17-03 물질의 경우 505개 전체 참여기관의 변이계수(\%)는 $7.0 \%$ 였지만, 최소값이 $0.69 \mu \mathrm{UU} /$
$\mathrm{mL}$, 최대값이 $42.21 \mu \mathrm{IU} / \mathrm{mL}$ 로 60 배 이상의 차이를 보였다. 이는 실제로 검사실간 결과가 큰 차이를 보였다기보다 검사결 과 입력 시 소수점을 잘못 찍었거나 결과보고 단위를 착각하 여 발생했을 것으로 추정된다. TSH검사와 같이 International System of Units (SI unit, mIU/L)과 conventional unit $(\mu \mathrm{IU} / \mathrm{mL}$ ) 사이에 conversion factor가 1 인 검사도 있지만, FT4 검사결과를 SI unit (pmol/L)으로 보고하기 위해서는 conventional unit (ng/dL)에 conversion factor인 12.9를 곱 해야 한다. TT3의 경우에는 conventional unit에서 SI unit 으로 변경할 때 conversion factor가 0.0154로 매우 작으므로 conventional unit의 결과를 그대로 입력하면 검사결과 차이 가 훨씬 크게 벌어질 수 있다. 따라서 개별기관에서 신빙도조

Table 4. Proficiency test results for hormone II in 2017

\begin{tabular}{|c|c|c|c|c|c|}
\hline Test & $\begin{array}{c}\text { No. of } \\
\text { participants }\end{array}$ & Quality control no. & $\begin{array}{c}\text { Mean } \pm \text { standard } \\
\text { deviation }\end{array}$ & $\begin{array}{l}\text { Coefficient of } \\
\text { variation }(\%)\end{array}$ & $\begin{array}{c}\text { Median } \\
(\min -\max )\end{array}$ \\
\hline \multicolumn{6}{|l|}{$1 s t$} \\
\hline \multirow[t]{3}{*}{ PTH } & 112 & CH-17-01 & $30.1 \pm 3.7$ & 12.4 & $30(21-52)$ \\
\hline & & $\mathrm{CH}-17-02$ & $486.7 \pm 37.4$ & 7.7 & $483(399-827)$ \\
\hline & & $\mathrm{CH}-17-03$ & $1058.4 \pm 73.3$ & 6.9 & $1,055(105-1,780)$ \\
\hline \multirow[t]{3}{*}{ Erythropoietin } & 7 & $\mathrm{CH}-17-01$ & $13.47 \pm 0.90$ & 6.7 & $13.7(0.80-14.4)$ \\
\hline & & $\mathrm{CH}-17-02$ & $58.76 \pm 0.43$ & 0.7 & $58.9(19.0-64.5)$ \\
\hline & & $\mathrm{CH}-17-03$ & $210.86 \pm 8.76$ & 4.2 & $210.0(104.8-242.0)$ \\
\hline \multirow[t]{3}{*}{ Vitamin D } & 131 & CH-17-01 & $9.08 \pm 4.69$ & 51.7 & $9.3(3.0-37.2)$ \\
\hline & & $\mathrm{CH}-17-02$ & $17.17 \pm 9.28$ & 54.0 & $15.1(3.0-33.4)$ \\
\hline & & $\mathrm{CH}-17-03$ & $57.40 \pm 28.06$ & 48.9 & $39.9(8.6-105.7)$ \\
\hline \multirow[t]{3}{*}{ Procalcitonin } & 142 & CH-17-01 & $0.588 \pm 0.021$ & 3.6 & $0.59(0.41-2.19)$ \\
\hline & & $\mathrm{CH}-17-02$ & $1.968 \pm 0.319$ & 16.2 & $1.81(0.42-8.86)$ \\
\hline & & $\mathrm{CH}-17-03$ & $18.705 \pm 3.078$ & 16.5 & $16.91(0.41-26.79)$ \\
\hline \multicolumn{6}{|l|}{ 2nd } \\
\hline \multirow[t]{3}{*}{ PTH } & 117 & $\mathrm{CH}-17-04$ & $30.9 \pm 3.0$ & 9.6 & $31(20-54)$ \\
\hline & & $\mathrm{CH}-17-05$ & $497.7 \pm 26.3$ & 5.3 & $495(412-1,180)$ \\
\hline & & $\mathrm{CH}-17-06$ & $1091.2 \pm 58.8$ & 5.4 & $1,086(950-1,900)$ \\
\hline \multirow[t]{3}{*}{ Erythropoietin } & 6 & $\mathrm{CH}-17-04$ & $15.12 \pm 1.68$ & 11.1 & $14.65(13.5-18.1)$ \\
\hline & & CH-17-05 & $63.82 \pm 4.22$ & 6.6 & $63.40(59.3-68.9)$ \\
\hline & & $\mathrm{CH}-17-06$ & $220.53 \pm 17.99$ & 8.2 & $220.6(195.0-246.0)$ \\
\hline \multirow[t]{3}{*}{ Vitamin D } & 135 & CH-17-04 & $8.14 \pm 4.61$ & 56.6 & $7.9(0-18.9)$ \\
\hline & & CH-17-05 & $15.12 \pm 8.79$ & 58.2 & $12.6(3.0-32.4)$ \\
\hline & & CH-17-06 & $53.96 \pm 28.73$ & 53.2 & $35.8(28.2-110.8)$ \\
\hline \multirow[t]{3}{*}{ Procalcitonin } & 149 & $\mathrm{CH}-17-04$ & $0.509 \pm 0.023$ & 4.5 & $0.51(0.28-1.20)$ \\
\hline & & CH-17-05 & $1.790 \pm 0.325$ & 18.1 & $1.59(1.43-4.31)$ \\
\hline & & $\mathrm{CH}-17-06$ & $20.028 \pm 3.439$ & 17.2 & $18.17(13.16-62.91)$ \\
\hline
\end{tabular}

Abbreviations: PTH, intact parathyroid hormone; vitamin D, total 25-hydroxy vitamin D. 


\section{Journal of LABORATORY MEDICINE and QUALITY ASSURANCE}

Hyung-Doo Park • Annual Report on KEQA for Hormones (2017)

사 검사결과를 입력할 때 임상검사정도관리협회에서 요구하 는 결과보고 단위에 맞추어 입력하지 않는 경우에는 오류가 발 생할 수 있다.

호르몬검사 II의 4가지 검사항목들 중 erythropoietin은 세 가지 정도관리물질에 대한 전체 참여기관의 변이계수(\%)가 0.7\%-6.7\%로 크지 않은 편이었는데, 참여기관의 수가 적은 것이 영향을 미쳤을 수 있다. 반면, Vit $\mathrm{D}$ 는 1 차 신빙도조사에 서 48.9\%-54.0\%의 변이계수 분포를, 2 차 조사에서 $53.2 \%-$ $58.2 \%$ 의 변이계수 분포를 보여서 기관들의 검사결과가 상당 히 폭넓게 분포하는 것을 볼 수 있었다. 다만 Vit $\mathrm{D}$ 의 동일 기 기회사별 통계에서는 3.9\%-13.8\%의 변이계수 분포를 보여서 같은 장비를 사용하는 기관들끼리는 비슷한 결과를 산출하고 있었다. 정확도가 높은 질량분석법으로 Vit D를 측정하는 기 관은 4곳으로 전체 131 기관의 $3 \%$ 수준에 불과하였으며, 대부 분의 기관에서는 면역측정법을 이용하고 있었다. 호르몬검사 는 아직까지 표준화나 일치화가 이루어지지 않은 경우가 많아 서 다른 회사 장비로 측정할 때에는 참고치와 측정가능범위 등 의 특성을 고려하여 해석할 필요가 있다. $\mathrm{PTH}$ 의 경우 1 차 조 사 시 전체 참여기관 112 곳의 평균은 $30.1 \mathrm{pg} / \mathrm{mL}$ 이었는데, Siemens 장비 사용기관(17곳)의 평균은 $26.8 \mathrm{pg} / \mathrm{mL}$ 이었던 반면에 Abbott 장비 사용기관(15곳)의 평균은 $45.0 \mathrm{pg} / \mathrm{mL}$ 로 Siemens 장비 사용기관들보다 $68 \%$ 더 높은 검사결과를 보였 다. 간혹 동일회사 그룹이나 동일기기 사용 그룹의 숫자가 적 어서 결과 적합성 여부를 판단하는 $\mathrm{SDI}$ 등 통계자료를 분석할 수 없는 경우에는 각 기관에서 전체 참여기관 자료 등을 참고 하여 결과가 허용범위에 드는지 여부를 개별적으로 판단하거 나, 검사실 간 비교를 수행하거나, 동료 그룹이 많은 국제적인 신빙도조사를 수행하는 등의 대체방법을 검토하는 것을 고려
할 필요가 있다.

호르몬검사 신빙도조사는 2016년부터 시행된 호르몬검사 I 프로그램에 이어 2017년부터 호르몬검사 II 프로그램이 추가 되어 총 15 가지의 검사항목으로 운영하고 있으며, 대부분의 항목에서 참여기관이 꾸준히 증가하고 있다.

\section{REFERENCES}

1. Jun SH, Song J, Song WH; Clinical Chemistry Subcommittee, Korean Association of External Quality Assessment Service. Annual report on the external quality assessment scheme for clinical chemistry in Korea (2015). J Lab Med Qual Assur 2016;38:111-9.

2. Jun SH, Song J; Clinical Chemistry Subcommittee, The Korean Association of External Quality Assessment Service. Annual report on the external quality assessment scheme for clinical chemistry in Korea (2014). J Lab Med Qual Assur 2015;37:115-23.

3. Jun SH, Song J; Clinical Chemistry Subcommittee; The Korean Association of Quality Assurance for Clinical Laboratory. Annual report on the external quality assessment scheme in clinical chemistry in Korea (2013). J Lab Med Qual Assur 2014;36:113-21.

4. Lee YW, Jeon BR, Kim JG, Jun SH, Yun YM, Chun S, et al. Annual report on the external quality assessment scheme for routine clinical chemistry in Korea (2016). J Lab Med Qual Assur 2017;39:61-75. 
Journal of LABORATORY MEDICINE and QUALITY ASSURANCE

Hyung-Doo Park • Annual Report on KEQA for Hormones (2017)

호르몬검사 프로그램 신빙도조사 결과보고(2017) 박형두

성균관대학교 의과대학 삼성서울병원 진단검사의학과

2017년 대한임상검사정도관리협회 신빙도조사사업에서 호르몬검사프로그램은 호르몬검사 1 에서 11 가지, 호르몬검사 $\|$ 에서 4 가지의 검사항목으로 운영되었다. 연 2회에 걸쳐 회차별로 3개의 정도 관리물질이 이용되었으며, 각 기관에서 입력한 검사항목에 대한 정보와 결과를 기반으로 검사기기 에 따라 분석하였다. 보고서는 전체 참여기관의 특성을 보여주는 공통보고서와 개별기관의 평가자 료를 보여주는 기관별 보고서로 나누어 작성하였다. 제시된 통계에는 각 그룹별 참여기관 수, 평균, 표준편차, 변동계수, 중앙값, 최소값과 최대값이 포함되도록 하였고, 기관별보고서는 각 검사항목별 로 통계치를 보여주는 표, 히스토그램과 레비-제닝스 차트로 구성되도록 하였다. 통계치를 제시한 표에는 각 기관의 검사결과와 분류별 통계치를 제시하고, 기준분류와 세분류에서는 표준편차지수 를 함께 제시하였다. 참여기관의 수와 검사장비의 분포에 있어서는 전체적으로 전년도와 큰 차이가 없었지만, 검사항목별로 참여기관의 수가 다양하였다. 회차별로 정도관리물질의 농도가 낮고 참여 기관의 수가 적을수록 변이계수는 상대적으로 높은 경향을 보였다. 각 기관에서 외부정도관리 결과 를 해석하고 호르몬검사 장비를 선택할 때 이 통계분석 자료가 유용할 것으로 생각한다.

(J Lab Med Qual Assur 2018;40:77-84)

교신저자: 박형두

우)06351 서울시 강남구 일원로 81 , 성균관대학교 삼성서울병원 진단검사의학과

Tel: 02)3410-0290, Fax: 02)3410-2719, E-mail: nayadoo@hanmail.net 